\title{
Efectividad de la formación de biofilms por cepas de pseudomona y su capacidad de disminución de cloro y antagónica de bacterias coliformes
}

\section{Effectiveness of biofilm formation by pseudomonas strains and their ability to decrease chlorine and antagonism of coliform bacteria}

\author{
Oliver Rodríguez, Edgardo Abadial, Alexis De La Cruz ${ }^{2} *$ \\ ${ }^{1}$ Estudiantes de Biología, Centro Regional de Azuero, Universidad de Panamá, ${ }^{2}$ Docente de Microbiología, Centro Regional de \\ Azuero, Universidad de Panamá
}

\begin{abstract}
Resumen La efectividad de formación de biofilms o "biopelícula" por cepas de Pseudomona y su capacidad de disminución del cloro y antagónica para bacterias coliformes, permite en gran medida, estudiar la capacidad de P. aeruginosa y P. fluorencens para formar biopelícula. Para el diseño experimental se utilizaron cuatro tanques con agua potable, a la cual se le adicionó Tiosulfato de sodio para eliminar las concentraciones de cloro. Para efectuar la formación de biofilms se colocaron cuatro estructuras en forma de " $\mathrm{T}$ " de PVC, sostenidas con alambre dulce. Se utilizaron tres tratamientos, uno con P. aeruginosa, otro con P. fluorencens y la mixtura (combinación de ambas cepas). Para cada tratamiento se realizaron conteos, caracterización y cuantificación de colonias bacterianas. Con el objetivo de determinar la efectividad de formación de biofilms por cepas de P. aeruginosa y P. fluorescens, así como también su capacidad de disminución del cloro y antagónica para bacterias coliformes. Nuestros Resultados indican que P. aeruginosa presentó una mayor capacidad para formar biofilms, en comparación con los demás tratamientos. El biofilms formado mostró efectividad en disminuir las concentraciones de cloro utilizadas, así como también, gran poder de antagonismo contra Escherichia coli. P. aeruginosa mostró mayor capacidad de antagonismo con un halo de $1 \mathrm{~mm}$ de diámetro. Hemos encontrado que las cepas de Pseudomona utilizadas producen biofilms eficientemente, el cual reduce las concentraciones de cloro.
\end{abstract}

Palabras clave Biofilms, cloro, desinfección.

Abstract The effectiveness of formation of biofilms or "biofilm" by strains of Pseudomonas and their capacity to reduce chlorine and antagonistic to coliform bacteria, allows to a large extent, study the ability of P. aeruginosa and P. fluorencens to form biofilm. For the experimental design four tanks with drinking water were used, to which sodium thiosulfate was added to eliminate chlorine concentrations. To make the formation of Biofilms, four PVC "T" structures were placed, supported with sweet wire. Three treatments were used, one with P. aeruginosa, another with P. fluorencens and the mixture (combination of both strains). Counting, characterization and quantification of bacterial colonies were carried out for each treatment. In order to determine the effectiveness of biofilm formation by strains of P. aeruginosa and P. fluorescens, as well as their capacity to reduce chlorine and antagonistic to coliform bacteria. Our results indicate that P. aeruginosa showed a greater capacity to form biofilms, in comparison with the other treatments. The strains showed effectiveness in decreasing the concentrations of chlorine used, as well as, great power of antagonism against Escherichia coli. P. aeruginosa showed greater antagonism capacity with a $1 \mathrm{~mm}$ diameter halo. We have found that the strains of Pseudomonas used produce biofilms efficiently, which reduces chlorine.

Keywords Biofilm, chlorine, desinfection.

*Corresponding author: alexisdelac@gmail.

Las bacterias existen en la naturaleza bajo dos formas o estados: a) bacterias planctónicas, de libre flotación, y b) bacterias formadoras de biofilms, en colonias de microorganismos sésiles [1]. El biofilm se define como comunidad de microorganismos que crecen embebidos en una matriz de exopolisacáridos y adheridos a una superficie inerte o un tejido vivo [2].

Cuando se corta una tubería de agua potable se puede observar la formación de un "limo" de color verde al cual denominamos biofilm. Esto nos trae a nuestras mentes muchas 
interrogantes: ¿Será esto dañino para nuestra salud? ¿Es normal?

La formación de biopelicula está dada por el ingreso de microorganismos a la red, los cuales se adhieren a las tuberías por medio de las Sustancias Poliméricas Extracelulares (EPS), el cual forma una matriz microbiana que se alimenta de nutrientes del agua y de la tubería, que a su vez absorbe compuestos inorgánicos. Dentro de esta matriz se dan procesos de reproducción y desprendimiento que conllevan a la formación de nuevos agregados en otros puntos de la red. La formación de la biopelícula afecta en gran medida los índices de cloro y el flujo de agua dentro de las redes de distribución [3]. El crecimiento bacteriano en los sistemas de almacenamiento y distribución de agua potable produce un deterioro de la calidad del agua, alterando su sabor y olor, aumentando la turbiedad e incluso puede llegar a afectar su conformidad con las normas microbiológicas de calidad [4].

Un biofilms desarrollado es muy resistente, y un problema cuando se precisa un entorno limpio y desinfectado. Los microbios del biofilms pueden significar un reservorio de bacterias, involucrarse en contaminaciones cruzadas, obturar las contaminaciones de líquidos, y poner serias dificultades a la higiene [5].

Pseudomonas constituyen un género específico de los bacilos, formado por bacterias oxidasa positivas (es decir, que producen esta enzima) y Gram negativas (ya que no adquieren una tonalidad azulada cuando se les aplica la coloración de Gram) [6].

El objetivo de esta investigación consistió en determinar la efectividad de formación de biofilms por cepas de P. aeruginosa y P. fluorescens, así como también, su capacidad de disminución del cloro y antagónica para bacterias coliformes.

\section{2.}

\subsection{Construcción y preparación del sistema para el diseño experimental}

Se utilizaron cuatro tanques con un volumen de $17,85 \mathrm{l} / \mathrm{c}$. Se utilizó cloro para limpiar las paredes internas de los tanques. A cada tanque se le adicionaron 14,28 1 de agua potable y $1 \mathrm{ml}$ de Tiosulfato de sodio, en cada uno de los tratamientos y el control, se colocaron cuatro estructuras en forma de " $\mathrm{T}$ " de PVC (Figura 1).

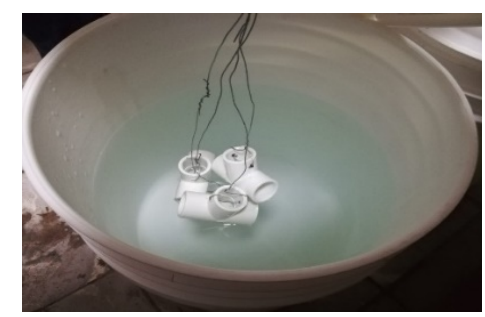

Figura 1. Estructuras en forma de "T" de PVC (1 Pulg) suspendidas en el tratamiento, se usaron para la formación de la biopelícula bacteriana o biofilms. 2.2. Inoculación bacteriana
Se utilizaron cepas de $P$. aeruginosa y $P$. fluorencens aisladas de cultivos puros e inoculadas en caldo Tripticasa de soja $(120 \mathrm{ml})$ por un periodo de 24 horas y posteriormente colocadas en los tratamientos ( $P$. aeruginosa, $P$. fluorencens y mixtura). Se agregó $10 \mathrm{ml}$ del inoculo con la ayuda de una micropipeta, cada tanque etiquetado con su respectiva identificación y tapados herméticamente para evitar su contaminación.

\subsection{Caracterización, formación y cuantificación de las colonias o cepas formadoras de biofilms}

\subsubsection{Caracterización y formación}

Para verificar el desarrollo de las cepas formadoras de biofilms se realizaron cultivos en agar Cetrimide para los tratamientos y el control, cada cuatro días después de haber inoculado las cepas en los tanques en dos ocasiones, se aplicó la técnica de hisopado sobre las "T" de PVC y con la ayuda de un asa bacteriológica se realizó el cultivo. Se anotaron aspectos morfológicos, como: elevación, tamaño, borde, color y consistencia de las colonias bacterianas.

\subsubsection{Cuantificación}

Para efectuar el conteo de colonias (UFC) en los tratamientos se realizaron diluciones en serie con tubos de ensayo de $10 \mathrm{ml}$, los cuales contenían $6 \mathrm{ml}$ de solución isotónica al 0,8 \%, se realizó el hisopado en las "T" de PVC para el control y cada tratamiento, se utilizaron tres tubos para cada uno, se etiquetó y a partir de esas diluciones se procedió hacer cultivos de los dos primeros tubos en agar Cetrimide. Luego de obtener el crecimiento se procedió a realizar el conteo, urilizando el contador de colonias bacterianas.

\subsection{Determinación de la capacidad fisiológica del biofilms}

El biofilms formado en la "T" de PVC por P. aeruginosa, $P$. fluorencens y en mixtura se enfrentó a diferentes concentraciones de cloro $(0.2 \mathrm{ppm}, 0.5 \mathrm{ppm}$ y $1.0 \mathrm{ppm})$ y utilizando un control para cada tratamiento $(0.6 \mathrm{ppm})$, se utilizaron cuatro envases con volumen de 3.781 para cada concentración, se colocaron 31 de agua en cada envase con las concentraciones de cloro antes mencionadas, en donde fueron colocadas las "T" de PVC. Se tomó lectura de cloro inicial, a las 12 y 24 horas. Los envases se taparon con papel aluminio para evitar cualquier tipo de contaminación.

\subsection{Capacidad antagónica ante cepas de coliformes}

Se realizaron dos pruebas por cada tratamiento. Se utilizó agar Bacteriológico y Tripticasa de soja en caldo. Se cortaron discos de papel filtro, los cuales fueron introducidos en tubos de ensayo con agua destilada estéril, se les inoculó $P$. aeruginosa, $P$. fluorencens y la mixtura obtenida de los tratamientos iniciales y luego se incubaron para su crecimiento a $37{ }^{\circ} \mathrm{C}$ por 24 horas. Esos discos fueron usados para medir la capacidad antagónica de cada una de las cepas contra 
crecimiento en placas Petri con E. coli, colocando discos impregnados de estas cepas bacterianas.

\section{Resultados y discusión}

En la caracterización morfológica de las colonias para los tratamientos se pudo determinar que las cepas utilizadas iban en constante desarrollo y ambas presentaban morfologías muy parecidas. Sin embargo, al ser utilizadas en mixtura las características obtenidas concuerdan en su totalidad con las de $P$. aeruginosa, lo cual muestra un dominio de esta bacteria contra $P$. fluorencens (tabla 1).

Tabla 1. Características morfológicas de las colonias cultivadas a los 4 días de haberse inoculado las cepas en los tratamientos

\begin{tabular}{lllll}
\hline Características & $\boldsymbol{P}$ & $\boldsymbol{P}$ & Control & Mixtura \\
& aeruginosa & fluorescens & & \\
\hline Elevación & Plana & Convexa & ----- & Plana \\
\hline Tamaño & Grandes & Pequeñas & ----- & Grandes \\
\hline Color & Crema & Crema & ----- & Crema \\
\hline Borde & Ondulado & Redondo & ----- & Ondulado \\
\hline Consistencia & Cremosa & Cremosa & ----- & Cremosa \\
\hline
\end{tabular}

De las cepas utilizadas, $P$. aeruginosa, presentó mayor capacidad de formación de biofilms, la cuantificación de colonias para este tratamiento fue altamente superior con respecto a los de $P$. fluorencens y mixtura. Sin embargo, al mezclar ambas cepas no presentaron gran cantidad de colonias (figura 2). La referencia [8] muestra que $P$. aeruginosa es el modelo bacteriano en el que se han realizado la mayoría de los estudios de formación de biofilms y regulación mediante quorum sensing (forma en que se comunican las bacterias). Es importante señalar que este es un estudio experimental, pero es necesario tomar en cuenta la capacidad de los microrganismos para formar biopelícula sobre cualquier material o sitio determinado, en este caso bacterias del género Pseudomona, las cuales muchas son patógenas para el ser humano.

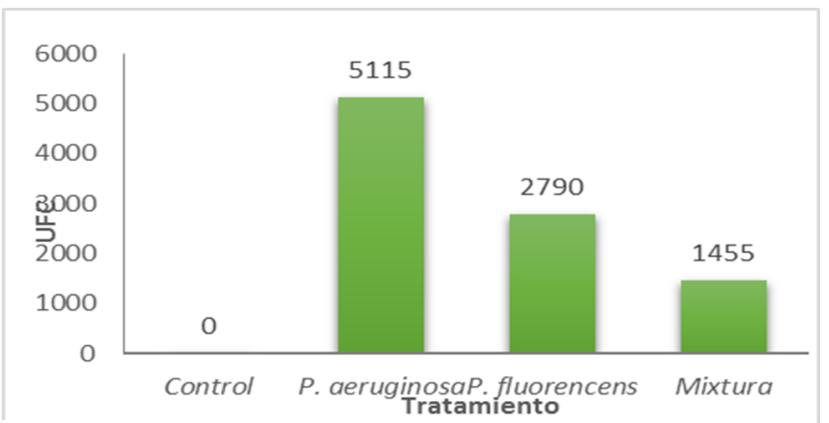

Figura 2. Cuantificación de colonias bacterianas (UFC) formadoras de biofilms en las estructuras en forma de "T" de PVC, 20 días después de haberse inoculado las cepas en cada tratamiento.
Para determinar la capacidad fisiológica y estructural del biofilms se realizó un ensayo, donde se someten las biopelículas formadas por los tratamientos ( $P$. aeruginosa, $P$. fluorencens y mixtura) a diferentes concentraciones de cloro, se realizan lecturas de la concentración de cloro inicial $(0$ horas); a las 12 horas y 24 horas. También, se utilizó un control, se obtuvo que las concentraciones de cloro disminuyeron totalmente para los tratamientos $P$. aeruginosa (figura 3), $P$. fluorescens (figura 4), y en mixtura (figura 5) y parcialmente para el control. La referencia [9] muestra que la investigación desarrollada en Francia demuestra que los procesos de desinfección química son solo parcialmente exitosos en la remoción del biofilms. Los bajos niveles de cloro en la red permiten que exista una alta carga de microorganismos circulando en el agua. Esto no solo se ve reflejado en un potencial problema de salud pública sino también en un problema técnico y económico, ya que existen microorganismos que han generado resistencias a los desinfectantes y que son potencialmente patógenos, lo que encarece el tratamiento e impide garantizar que el agua sea potable en todos los puntos de la red [7].

Hace falta comprobar más a fondo si las bacterias del género Pseudomona, y otros microrganismos desarrollan la capacidad de disminuir agentes químicos como el cloro y cuáles mecanismos utilizan. Posiblemente la disminución de cloro obtenida haya sido debido al biofilms formado por las cepas de Pseudomona, ya que existen otros factores como la volatilización, turbidez, $\mathrm{pH}$ y temperatura que pueden tener un efecto en la disminución de este.

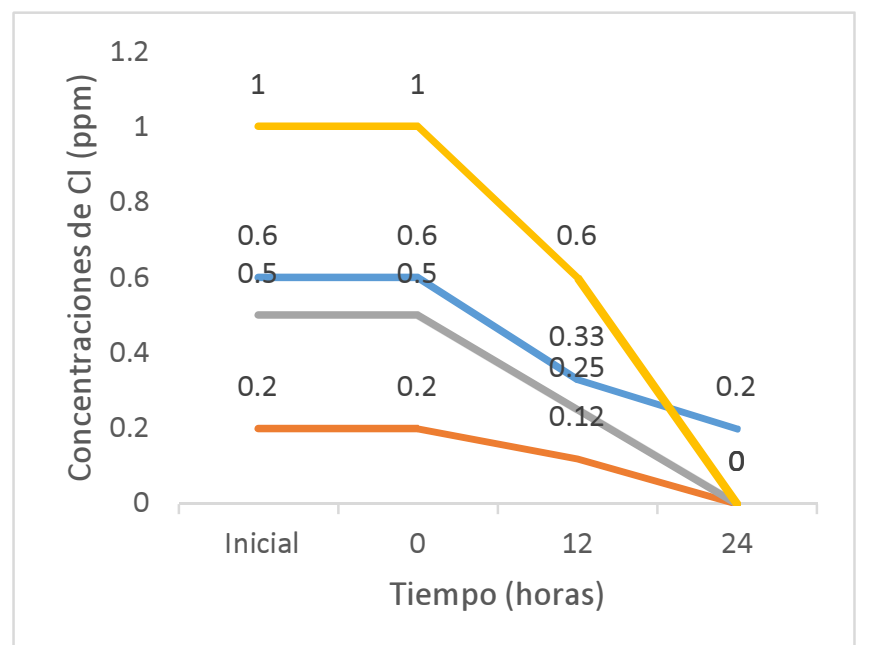

Figura 3. Biofilms formado por $P$. aeruginosa enfrentado a diferentes concentraciones de $\mathrm{Cl}$. 


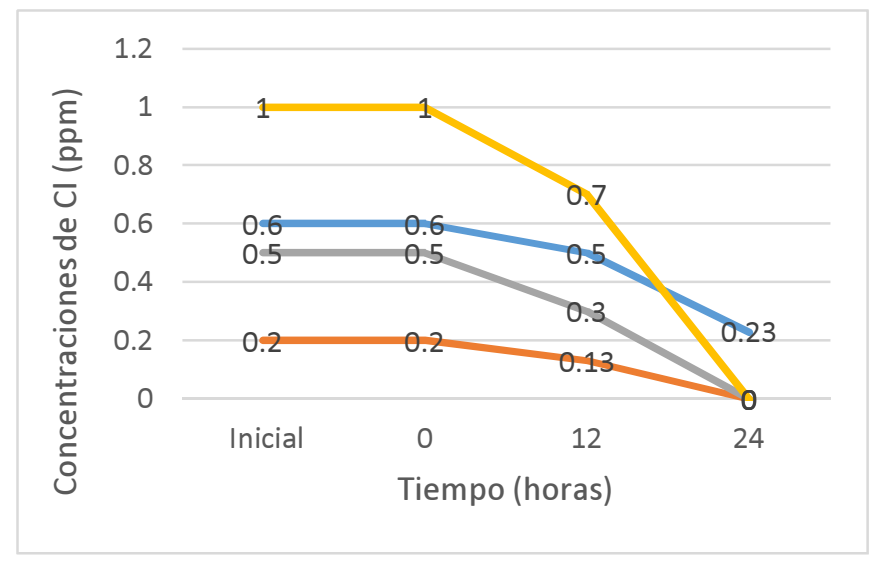

Figura 4. Biofilms formado por P. fluorescens enfrentado a diferentes concentraciones de $\mathrm{Cl}$.

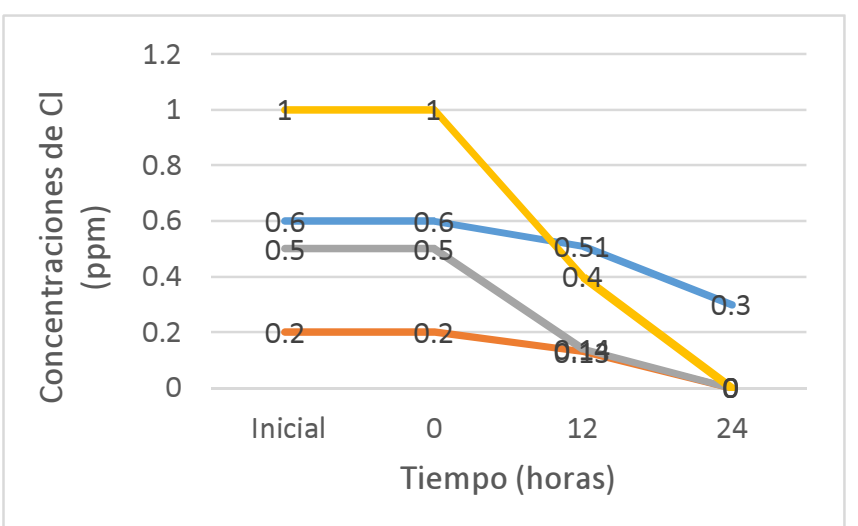

Figura 5. Biofilms formado por la mixtura enfrentado a diferentes concentraciones de $\mathrm{Cl}$.

Las pruebas de antagonismo contra Escherichia coli muestran una efectividad en todos los tratamientos utilizados, cuyos espacios de inhibición resultan entre 0,9 a $1 \mathrm{~mm}$ de diámetro (tabla 2), lo cual concuerda con los resultados obtenidos por Ysasis y Flores, en donde comprobó que, $P$. aeruginosa produce antagonismo contra otros microrganismos [10]. Vale la pena diversificar este estudio, para determinar los metabolitos producidos por estas bacterias y la aplicación que puedan tener, por ejemplo, el biocontrol. También, evaluar el antagonismo contra otras especies de bacterias.

Tabla 2. Efectividad de antagonismo por las cepas de Pseudomona contra E. coli

\begin{tabular}{|l|c|}
\hline Tratamientos & $\begin{array}{l}\text { Diámetro de halo } \\
\text { de antagonismo } \\
(\mathbf{m m})\end{array}$ \\
\hline P. aeruginosa & 1 \\
\hline P. fluorencens & 0.9 \\
\hline Mixtura & 1 \\
\hline
\end{tabular}

\section{Conclusiones}

$P$. aeruginosa presentó mayor capacidad para formar biofilms en comparación con los demás tratamientos, se obtuvo disminución del cloro. P. aeruginosa, P. fluorencens y en mixtura desarrollaron poder antagónico contra la bacteria Escherichia coli, el cual fue mayor para $P$. aeruginosa y la mixtura.

Se deben realizar estudios más profundos para verificar si esta disminución es debida a los microorganismos o se puede deber a otros factores, como: volatilización, temperatura, turbidez, etc.

Es importante comprobar profundamente si ciertas bacterias tienen la capacidad de reducir el cloro, y de esta manera pueden ser utilizadas para eliminar este elemento en el producto final de las plantas de tratamiento de aguas residuales, y evaluar los índices de cloro adicionados en las plantas de tratamiento de agua potable y al llegar a nuestros hogares, ya que, las biopelículas pueden tener un efecto en la disminución de este.

Las limitaciones de nuestro proyecto recaen en el espacio, tiempo y el requerimiento de mejores equipos de laboratorio y reactivos.

Este estudio abre las puertas a la realización de nuevas investigaciones relacionadas con la formación de biofilms sobre cualquier objeto, tejido o material y las implicaciones que pueda tener en la salud del ser humano, así como también, evaluar las formaciones de biopelículas en las redes de distribución de agua potable y el papel que desempeña en este sitio.

\section{AGRADECIMIENTOS}

Primeramente, darle gracias a Dios Todopoderoso por mantenernos con salud, motivación y dedicación para llevar a cabo este proyecto.

Al profesor Alexis De La Cruz por ser nuestro coordinador y brindarnos sus conocimientos en técnicas de microbiología, metodología, redacción, etc.

Al profesor Ítalo Goti por apoyarnos en la redacción del artículo.

Al Ministerio de Salud por permitirnos desarrollar la fase experimental del proyecto en el Laboratorio de Calidad de Agua en la Villa de Los Santos.

A la Secretaria Nacional de Ciencia, Tecnología e Innovación de Panamá (SENACYT), ya que, el autor (1) del presente escrito es becado de dicha institución.

\section{REFERENCIAS}

[1] J. Nazar C, «Biofilms bacterianos», Revista de otorrinolaringología y cirugía de cabeza y cuello, vol. 67, n.o 1 , pp. 161-172, abr. 2007.

[2] I. Lasa, J. L. del Pozo, J. R. Penadés, y J. Leiva, «Biofilms bacterianos e infección», Anales del Sistema Sanitario de Navarra, vol. 28, n.o 2, pp. 163-175, ago. 2005. 
Abadia (et al): Efectividad de la formación de biofilms por cepas de pseudomona y su capacidad de disminución de cloro y antagónica de bacterias coliformes

[3] «519». [En línea]. Disponible en: https://docs.google.com/viewerng/viewer?url=http://ojsrevi staing.uniandes.edu.co/ojs/index.php/revista/article/viewFile/3 5/519. [Accedido: 10-ago-2018].

[4] J. K. Miranda y R. M. Sahuquillo, «Crecimiento bacteriano en las redes de distribución de agua potable: una revisión bibliográfica», Ingeniería del agua, vol. 4, n.o 2, jun. 1997.

[5] G. P. Serra, «Formación y Consecuencias», p. 27.

[6] «Definición de pseudomonas - Definicion.de», Definición.de. [En línea]. Disponible en: https://definicion.de/pseudomonas/. [Accedido: 10-ago-2018].

[7] J. C. R. Ariza, A. J. Martínez, y D. C. Calvo, «Efecto del desprendimiento de las biopelículas formadas en una red de acueducto sobre la calidad del agua», Revista de Ingeniería, p. 6, 2013.
[8] S. Téllez, «Los Biofilms y su repercusión en la Industria Alimentaria», VISAVET Outreach Journal, may 2010.

[9] G. González, M. Isabel, M. García Melián, M. Alonso, y M. de los Ángeles, «Importancia sanitaria de Pseudomonas aeruginosa en agua de hemodiálisis y su desinfección», Revista Cubana de Salud Pública, vol. 40, n.o 2, pp. 198-211, jun. 2014.

[10] L. A. Ysasis y E. Flores, «Actividad antagónica en aislamientos clínicos de Pseudomonas aeruginosa», UNIVERSIDAD DEL ZULIA, vol. 14, p. 8, 2014. 